MacDonald, W.C., Trier, J.S. \& Everett, N.B. (1964) Cell proliferation and migration in the stomach, duodenum and rectum of man: radioautographic studies. Gastroenterology, 46, 405.

MiLne, M.D. (1967) Hereditary abnormalities of intestinal absorption. Brit. med. Bull. 23, 279.

PoRUs, R.L. (1965) Epithelial hypoplasia following massive small bowel resection in man. Gastroenterology, 48, 753.

Reiner, E. \& PAtTerson, H. (1966) The effects of neomycin on disaccharidase activity of the small bowel. Clin. Res. 14, 499.

Riecken, E.O., Dowling, H., Booth, C.C. \& Pearse, A.G.E. (1965) Histochemical changes in the rat small intestine associated with enhanced absorption after high bulk feeding. Enzymol. biol. clin. 5, 231.
Shorter, R.G., Moertel, C.B., Titus, J.L. \& Reitemeier, R.J. (1964) Cell kinetics in the jejunum and rectum of man. Amer. J. digest. Dis. 9, 760.

SмYтH, D.H. (1967) Intestinal absorption. Brit. med. Bull. 23, 207.

Stevens Hooper, C. \& Blair, M. (1958) The effect of starvation on epithelial renewal in the rat duodenum. Exp. Cell Res. 14, 175.

Trier, J.S. \& BrownING, T.H. (1966) Morphological response of the mucosa of human small intestine to $\mathrm{X}$-ray exposure. J. clin. Invest. 45, 194.

ZAMCHEK, N. (1960) Dynamic interaction among body nutrition, gut mucosal metabolism and morphology and transport across the mucosa. Fed. Proc. 19, 855.

\title{
Distribution of diffusing capacity in obstructive lung disease
}

\author{
William A. BRiscoe \\ Columbia Medical Division of Bellevue Hospital; Department of Medicine, \\ College of Physicians and Surgeons, Columbia University, New York City
}

While I was a registrar at Hammersmith, Professor McMichael remarked one day, 'Why don't you do something about emphysema?' This led to my introduction to McMichael's method.

\section{McMichael's method}

It is sometimes forgotten that McMichael was initially best known in the field of respiration rather than circulation. In 1939, he described his new closed-circuit spirometer for measuring the functional residual capacity of the lungs (McMichael, 1939). The four novel features he introduced, partly in collaboration with Herrald (Herrald \& McMichael, 1939), were: (1) the maintenance of constant volume in the spirometer, from which a patient breathed for many minutes by adding oxygen at a rate equal to its metabolic consumption; (2) a pump was used to circulate and mix the gases rapidly in the spirometer ; (3) the re-breathing period was prolonged beyond the usual $7 \mathrm{~min}$, when the patient's lungs mixed slowly with the gas in the spirometer ; and (4) an insoluble inert gas, hydrogen or helium, was used as the indicator, and estimated by its thermal conductivity. These innovations resulted in what is still, 28 years later, the best and most widely used method; it should perhaps be more widely referred to as McMichael's Method (Briscoe, 1965).

\section{Bad mixing}

Herrald \& McMichael (1939) had emphasized that in some patients, the mixing of inert gases between lungs and spirometer took much longer than normal. This had been a technical bugaboo in previous methods of lung volume measurement. It now seemed worth while to study this source of technical error as an interesting and perhaps important aspect of pathophysiology. The conclusions from this Hammersmith work were: normal lungs mixed helium from the McMichael spirometer as if they were nearly evenly ventilated. In patients incapacitated by bronchitis and emphysema, the behaviour of the lung could be almost exactly simulated by a simple two-chamber model, composed of two differently ventilated bellows or balloons in parallel. The well-ventilated bellows was small with a volume of about 1 litre, and ventilated by about $450 \mathrm{ml}$ breath. The poorly ventilated bellows was large with a volume of 3-5 litres, and ventilated by only $50 \mathrm{ml}$ breath (Briscoe, Becklake \& Rose, 1951 ; Briscoe, 1952; Briscoe \& McLemore, 1952). A lung of this type, with a normal volume of conducting airways, behaves as if it had a large physiological dead spacea simpler but less complete description of the real state of affairs.

We were not the only ones to recognize that uneven ventilation was the key to understanding the disturbance of function in obstructive lung disease: in the United States, Robertson, Siri \& Jones (1950) and Fowler, Cornish \& Kety (1952) published their classic studies of the distribution 
of ventilation, as intrapulmonary mixing is now called, measured by nitrogen washout during prolonged oxygen breathing. Their findings were the same: a large volume, more than half, of the emphysematous lung was very poorly ventilated: a small part was over-ventilated. Total ventilation was normal or more than normal.

\section{Clinical types of obstructive disease}

We now recognize perhaps more clearly than we did at Hammersmith in 1950, that there are at least two recognizable extremes in the spectrum of chronic obstructive lung disease, desscribed by Nash, Briscoe \& Cournand (1965) among many others (Fletcher et al., 1963). Most cases lie between these extremes: At one extreme called Type $\mathbf{A}$, is a thin man (eating increases his breathlessness), constantly dyspnoeic, obviously hyperventilating, with faintly heard breath sounds and heart sounds, a small heart, low flat diaphragms, hyperlucent lungs, a good pink colour and a normal haematocrit. He leads an unhappy breathless life as an out-patient without needing hospital admission over many years. When he develops arterial oxygen unsaturation, he is finally admitted to hospital with intractable right heart failure. At autopsy, the lungs are emphysematous.

At the other extreme, Type B, is a man of normal body build, whose dyspnoea is not so constant and distressing, varying considerably with his degree of bronchial infection. His breath sounds are of normal intensity, his heart is normal in size or enlarged; lung-fields and diaphragms appear normal in the X-ray. He is often cyanosed and has a raised haematocrit. Unlike the Type A patient, who is miserably breathless with normal arterial blood gases, the Type B patient has somehow learned how to be relatively happy, and even to work, while his blood gases are abnormal. He has repeated hospital admissions during episodes of increased respiratory insufficiency and right heart failure, from which he usually recovers, unlike Type A. At autopsy, Type $B$ tends to have bronchitis and centrilobular emphysema.

\section{Recent findings}

Dr Thomas King and I have recently developed the use of Bohr integral isopleths (King \& Briscoe, 1967) to deal with the distribution of two entities not considered in the early Hammersmith work on ventilation and lung volumes. These are the diffusing capacity (recently dubbed transfer factor or transfer coefficient) and blood flow in the differently ventilated lung spaces.

Data needed in each patient include the oxygen consumption, $\mathrm{CO}_{2}$ production, tidal volume and respiratory rate, and a nitrogen washout study during oxygen breathing to quantitate the uneven ventilation of the lung. Also needed, is arterial oxygen saturation (Sa), or $\mathrm{Po}_{2}$, and $\mathrm{PCO}_{2}$, while breathing air, 24, 30 and $100 \%$ oxygen: the figure gives these measured saturations. From this data, the distribution of ventilation, of lung volume, of blood flow and of diffusing capacity, can be worked out.
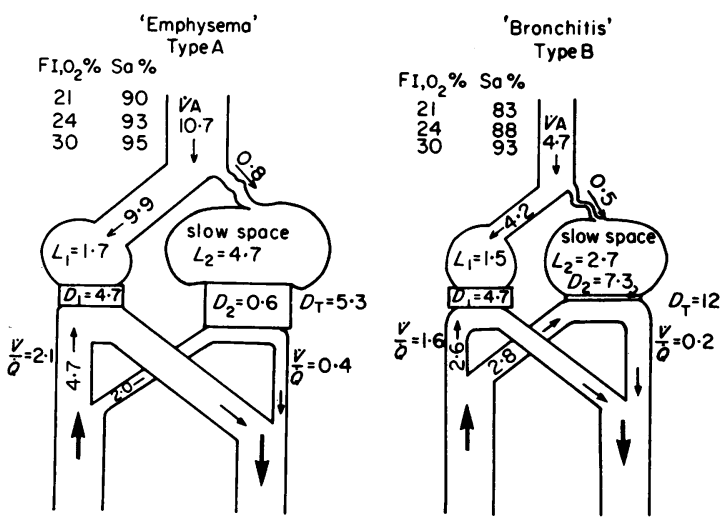

FIG. 1

Figure 1 presents the results in typical, equally incapacitated patients, of Type $\mathbf{A}$ and Type $\mathbf{B}$ (Briscoe \& King, 1967). The balloons do not represent the two lungs: their size is proportional to the volume of the groups of differently functioning lung spaces scattered through both lungs. The size of the airways and blood vessels is proportional to the volumes of gas or blood flowing through them. The thickness of the blocks between alveolar gas and pulmonary capillary blood is inversely proportional to the diffusing capacity. In both $\mathbf{A}$ and $\mathbf{B}$, the poorly ventilated lung spaces (slow space) constitute about two-thirds or three-quarters of the lung volume and receive only about one-tenth of the ventilation. In both, the diffusing capacity of the well-ventilated spaces $\left(D_{1}\right)$ is $4.7 \mathrm{ml} / \mathrm{min}$. $\mathrm{mmHg}$ and about what one would expect in spaces occupying, as these do, about one-third or one-quarter of the lung. But there the similarity stops. In Type $A$, lung volumes $\left(L_{1}\right.$ and $L_{2}$ ) are larger and so is the ventilation of both the lung spaces in Fig. 1. In Type A, the diffusing capacity in the slow space $\left(\mathrm{D}_{2}\right)$ is very low, $0.6 \mathrm{ml} / \mathrm{min} . \mathrm{mmHg}$, instead of being about $7 \mathrm{ml} / \mathrm{min} \cdot \mathrm{mmHg}$, as one would expect in threequarters of the lung. The total diffusing capacity of the whole lung $\left(D_{1}+D_{2}=D_{T}\right)$ is low because 
of the smallness of the component contributed by the slow space. This patient, in whom a large part of the lung has a low diffusing capacity, a low blood flow and very little ventilation, can be regarded as having had a sort of pneumonectomy by disease, so far as function is concerned. His oxygen uptake from alveolar gas into blood is largely in that small part of the lung which is well ventilated, and by hyperventilating he can maintain a normal arterial oxygen saturation while breathing air, for years.

In the Type B, the diffusing capacity in the slow space is high, and indeed the total diffusing capacity of all the lung spaces $\left(D_{T}\right)$ is virtually normal when measured by this four-gas method. Unlike Type A, there is a relatively large bloodflow to the slow space. Hence, there is a critically low ventilation/perfusion ratio $(V / Q=0 \cdot 2)$, with the result that this large quantity of pulmonary venous blood-flow is very poorly oxygenated, resulting in oxygen unsaturation of mixed arterial blood. Furthermore, insofar as the reduction in ventilation of the slow space is due to airway obstruction due to retained bronchial secretions, this patient's arterial oxygen unsaturation varies greatly with the quality and quantity of these secretions during mild execarbations or remissions in his chronic bronchitis. Unlike the Type A patient, in whom arterial oxygen unsaturation, if any, is largely the result of a low diffusing capacity, the defective blood gas exchange in the Type B patient is due to extreme unevenness of ventilation/perfusion ratios.

The ideas, given here in simplified form, will not save lives. However, they may help to stimulate the interest of physicians in patients who are sometimes considered to have an uninteresting disease, for which little can be done. Since these particular ideas, whether right, wrong, or in between, are a development of McMichael's early interest in obstructive lung disease, it seemed appropriate to the author to select them for inclusion in this Festschrift.

\section{Acknowledgments}

This work was supported by National Heart Institute Grants HE 02001-09 and HE 05741, and by the Health Research Council of the City of New York under Contract U-1067.

\section{References}

BRISCOE, W.A. (1952) Further studies on the intrapulmonary mixing of helium in normal and emphysematous subjects. Clin. Sci. 11, 46.

Briscoe, W.A. (1965) Lung volumes. Handbook of Physiology: Respiration II, Chap. 53, pp. 1345-1379. American Physiological Society, Washington.

BRISCOE, W.A., BECKLAKe, M.R. \& ROSE, T.F. (1951) Intrapulmonary mixing of helium in normal and emphysematous subjects. Clin. Sci. 10, 37.

BRISCOE, W.A. \& KING T.K.C. (1967) The diffusing capacity of the lung in obstructive disease: studied with the aid of Bohr integral isopleths. Amer. Rev. resp. Dis. 95, 891.

Briscoe, W.A. \& MCLemore, G.A. (1952) Ventilatory function in bronchial asthma. Thorax, 7, 66.

Fletcher, C.M., Hugh-Jones, P., McNicol, N.W. \& Pride, N.B. (1963) The diagnosis of emphysema in the presence of chronic bronchitis. Quart. J. Med. 32, 33.

Fowler, W.S., CoRnish, E.R. \& KeTY, S.S. (1952) Lung function studies. VIII. Analysis of alveolar ventilation by pulmonary $\mathrm{N}_{2}$ clearance curves. J. clin. Invest. 31, 40.

Herrald, F.J.C. \& McMichael, J. (1939) Determination of lung volume, a simple constant volume modification of Christie's method. Proc. roy. Soc. B, 126, 491.

KING, T.K.C. \& BRISCOE, W.A. (1967) Bohr integral isopleths in the study of blood gas exchange in the lung. $J$. appl. Physiol. 22, 659.

McMichael, J. (1939) A rapid method for determining lung capacity. Clin. Sci. 4, 167.

Nash, E., Briscoe, W.A. \& Cournand, A. (1965) The relationship between clinical and physiological findings in chronic obstructive disease of the lungs. Med. Thorac. 22 , 305.

Robertson, J.S., Siri, W.E. \& Jones, H.B. (1950) Lung ventilation patterns determined by analysis of nitrogen elimination rates; use of the mass spectrometer as a continuous gas analyser. J. clin. Invest. 29, 577. 